\title{
Preparation and Surface Active Properties of Alkali Salts of $N$-Perfluorooctanoylamino Acids
}

\author{
Chikai Kimura, Kageaki Kashiwaya, Mitsunobu Kobayashi, \\ Koichi MURAI*, and Tatsuo NisHIYAMA*** \\ Department of Chemical Engineering for Resources, Mining College, \\ Akita University (1-1, Gakuen-cho, Tegata, Akita) \\ * Department of Fuel Chemistry, Mining College, Akita University \\ (1-1, Gakuen-cho, Tegata, Akita) \\ ** Now Akita Chemical Company (13-1-6, Barajima, Akita)
}

Ethyl perfluorooctanoate was reacted at $30^{\circ} \mathrm{C}$ for $2 \mathrm{~h}$ in ethanol with ethyl ester of amino acid (glycine, $\alpha$-and $\beta$-alanine) to prepare $N$-perfluorooctanoylamino acid ester. The esters thus prepared were saponified to form the desired surface active agents by atidification with hydrochloric acid and successive neutralization with alkali hydroxides. The aqueous solution of these surfactants were subjected to the determination of surface tension, critical micelle concentration, Krafft point, wetta $=$ bility and oil repellency according to the conventional methods. Generally, the glycine derivatives were only slightly soluble in water showing higher Krafft points and poor surface activities. The $\alpha$-alanine derivatives showed lower Krafft point due to the presence of methyl side chain and superior wettability to other amino acid derivatives. The $\beta$-alanine derivatives exhibited significant surface tension depression and in the case of $K$ salt the surface tension was depressed to $15 \mathrm{dyn} / \mathrm{cm}$.

\section{Introduction}

It has long been known that the $N$-acylated amino acids ${ }^{1)}$ type surfactants have been pres pared by the condensation of fatty acid deri= vative with amino acid or hydrolysate of natural protein, and marketed under the name such as Medialan (Höchst) or Lamepon. As has been described in the recent review ${ }^{2)}$, (Chem, Fabrik Grünau) these materials are now gaining more interest and commercial use because of their good detergency and lime soap dispersant pro= perties. In addition, they are nonirritating to skin and thus useful for cosmetic and toile= tries $^{3}$.

On the other hand, the recent development of organic fluorine-containing compounds has included the preparation and application of fluorinated surfactant ${ }^{4}$. However, little infor= mation has been reported about the surfactants derived from perfluoro carboxylic acid and amino acid.

As part of the investigation of the preparas tion and properties of perfluoroamide-linked surfactants ${ }^{5) \sim 7)}$, an attempt has been made at this time to obtain the $N$-acylated amino acid salt using ethyl perfluorooctanoate and typical amino acids such as glycine, DL- $\alpha$-alanine and $\beta$-alanine according to the following reaction sequence.

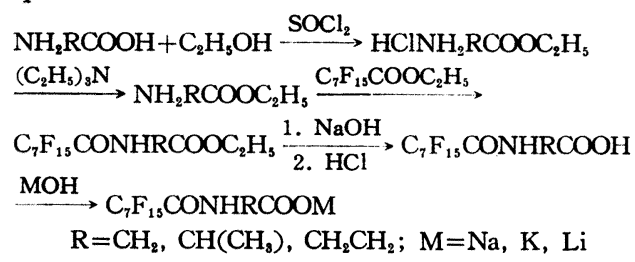

Thus, nine kinds of surfactants have been prepared with a good yield in each step and their surface active properties were determined and compared with each other.

\section{Experimental}

\subsection{Materials}

Amino acids employed in the experiment were obtained commercially and used without further purification. Ethyl perfluorooctanoate was prepared according to the known procedure described in the previous publication ${ }^{7)}$ and characterized regarding bp $172 \sim 174^{\circ} \mathrm{C}, \quad n_{\mathbf{D}}^{20}$ 1.3124; $\operatorname{IR}\left(\mathrm{cm}^{-1}\right), \quad 1780 \quad(\mathrm{C}=\mathrm{O}), \quad 1100 \sim 1300$ 
(CF).

\subsection{Method of preparation}

\section{$2 \cdot 2 \cdot 1$ Ethyl ester of amino acid}

Amino acid was esterified by ethyl alcohol according to the method adopted in the pres paration of benzyl ester ${ }^{8)}$.

Thionyl chloride $(26.2 \mathrm{~g}, 0.22 \mathrm{~mol})$ was added with stirring to an ethanol solution $(200 \mathrm{ml})$ of amino acid $(0.22 \mathrm{~mol})$ at $(200 \mathrm{ml}) \quad 0 \sim 5^{\circ} \mathrm{C}$. After the addition, stirring was continued for further $2 \mathrm{~h}$ at $40^{\circ} \mathrm{C}$. The reaction mixture was cooled to room temperature, diluted with ethyl ether until turbidity appeared and then refri= gerated for about $3 \mathrm{~h}$. The solid material was filtered off and recrystallized from ether-ethanol mixed solvent.

The amino acid ester hydrochloride $(0.1 \mathrm{~mol})$ thus obtained was dissolved in $100 \mathrm{ml}$ of chloroform and a large excess amount of triethylamine was added to the solution dro= pwise over a period of $10 \mathrm{~min}$ and stirring was continued for about $3 \mathrm{~h}$. Chloroform was eva= porated in reduced pressure and the product was distilled off in racuo.

$2 \cdot 2 \cdot 2 \quad$ N-Perfluorooctanoylamino acid ethyl ester

Ethyl perfluorooctanoate $(13.2 \mathrm{~g}, 0.03$ mol) was dissolved in $20 \mathrm{ml}$ of ethanol and the solution was added to the amino acid ethyl ester $(0.03 \mathrm{~mol})$ in ethanol $(10 \mathrm{ml})$. The reaction mixture was stirred at $30^{\circ} \mathrm{C}$ for about $2 \mathrm{~h}$. Then, the solvent was evaporated in reduced pressure and the residue distil= led in vacuo.

$2 \cdot 2 \cdot 3 \quad N$-Perfluorooctanoylamino acid

The above ester $(0.04 \mathrm{~mol})$ was mixed with sodium hydroxide $(1 \mathrm{~g}, 0.004 \mathrm{~mol})$ dissolved in $50 \mathrm{ml}$ of water and stirred at $80^{\circ} \mathrm{C}$ for $1 \mathrm{~h}$. Aqueous hydrochloric acid $(9 \%)$ was added to the mixture cooled in the ice-water bath until the solution hecamt acidic. The product separated was filtered off, washed with water and recrystallized from acetoni= trile.

$2 \cdot 2 \cdot 4$ Alkali metal salt of $N$-per= fluorooctanoylamino acid

N.Perfluorooctanoylamino acid was neutralized with aqueous alkali hydroxide and the solution was evaporated to dryness to obtain the corresponding alkali salt.

\section{$2 \cdot 3$ Measurement of surface active pro perties}

Surface tension was measured at $30^{\circ} \mathrm{C}$ using the Wilhelmy type tensiometer and the values obtained were plotted against the concentration of surfactant. The critical micelle concentration (cmc) was determined by the conductivity method and the Krafft point was showned by the temperature at which $1 \%$ suspension became clear solution. Wettability was estimated by the sinking time determined by the canvas disk test. Oil repellency was determined according to the $3 \mathrm{M}$ Oil Repellency Test ${ }^{9}$.

\section{Results and Discussion}

\subsection{Preparation of intermediates}

The amino acid ethyl ester was prepared in $55 \sim 78 \%$ yield, though a part of the product was polymerized, from the corresponding hydro= chloride obtained in excellent yield (83 93\%) by esterification of the amino acid with ethyl alcohol in the presence of thionyl chloride. The properties of the amino acid ethyl esters and

Table-1 Properties of amino acid derivatives.

\begin{tabular}{c|c|c|c}
\hline \multirow{2}{*}{$\mathrm{R}$} & $\mathrm{HCINH}_{2} \mathrm{RCOOC}_{2} \mathrm{H}_{5}$ & \multicolumn{2}{|c}{$\mathrm{NH}_{2} \mathrm{RCOOC}_{2} \mathrm{H}_{5}$} \\
\cline { 2 - 4 } & $\mathrm{mp}\left({ }^{\circ} \mathrm{C}\right)$ & $\mathrm{bp}\left({ }^{\circ} \mathrm{C} / \mathrm{mmHg}\right)$ & $n_{\mathrm{D}}^{20}$ \\
\hline $\mathrm{CH}_{2}$ & $143 \sim 144$ & $41 \sim 42 / 7$ & 1.4237 \\
$\mathrm{CH}\left(\mathrm{CH}_{3}\right)$ & $85 \sim 86$ & $40 \sim 42 / 9$ & 1.4185 \\
$\mathrm{CH}_{2} \mathrm{CH}_{2}$ & $55 \sim 56$ & $51 \sim 52 / 9$ & 1.4267 \\
\hline
\end{tabular}

Table-2 Properties of $N$-perfluorooctanoylamino acids and their ethyl esters.

\begin{tabular}{|c|c|c|c|}
\hline \multirow{2}{*}{$\mathrm{R}$} & \multicolumn{3}{|c|}{$\mathrm{C}_{7} \mathrm{~F}_{15} \mathrm{CONHRCOOC}{ }_{2} \mathrm{H}_{5}$} \\
\hline & bp $\left({ }^{\circ} \mathrm{C} / \mathrm{mmHg}\right)$ & $\mathrm{mp}\left({ }^{\circ} \mathrm{C}\right)$ & IR $\left(\mathrm{cm}^{-1}\right)$ \\
\hline $\mathrm{CH}_{2}$ & $118 \sim 121 /: 3$ & $29 \sim 30$ & 3330,1740 \\
\hline $\mathrm{CH}\left(\mathrm{CH}_{3}\right)$ & $116 \sim 117 / 3$ & $32 \sim 33$ & 1700,1550 \\
\hline $\mathrm{CH}_{2} \mathrm{CH}_{2}$ & $120-1232$ & $31-32$ & $1: 300 \sim 1100$ \\
\hline \multirow{2}{*}{$k$} & \multicolumn{3}{|c|}{$C_{7} \mathrm{~F}_{15} \mathrm{CONHRCOOH}$} \\
\hline & $\mathrm{mp}(\mathrm{C})$ & (Calcd) & $\mathrm{RI}\left(\mathrm{cm}^{1}\right)$ \\
\hline $\mathrm{CH}_{2}$ & $134 \sim 135$ & (119.0) & $\begin{array}{l}3300 \sim 3290 \\
1720 \sim 1710\end{array}$ \\
\hline $\mathrm{CH}\left(\mathrm{CH}_{3}\right)$ & $168 \sim 169$ & $5(115.6)$ & $\begin{array}{l}1690 \\
1550 \sim 1530\end{array}$ \\
\hline $\mathrm{CH}_{2} \mathrm{CH}_{2}$ & $121 \sim 122$ & () (115.6) & $1300 \sim 1100$ \\
\hline
\end{tabular}


their hydrochlorides were shown in Table-1.

The amino acid ethyl ester was reacted with ethyl perfluorooctanoate to obtain $N$-perfluoro= octanoylamino acid ester in 64 91\% yield. The ester thus obtained was converted to the corresponding acid as a white crystal in 66 99 $\%$ yield. The properties of these $N$-perfluoro= octanoyl compounds were shown in Table-2.

\section{$3 \cdot 2$ Surface tension}

The surfactants prepared at this time showed great ability of surface tension reduction in accordance with the general feature of the fluorine-containing surfactant. Among the three kinds of amino acid derivatives, the glycine derivatives were found to be generally poorly soluble in water and inferior to other amino acid derivatives in surface tension reduction (Figs.-1, 2), although the lithium-containing derivative exhibited a greater efficiency as shown in Fig. -3 . On the contrary, $\alpha$ - and $\beta$.

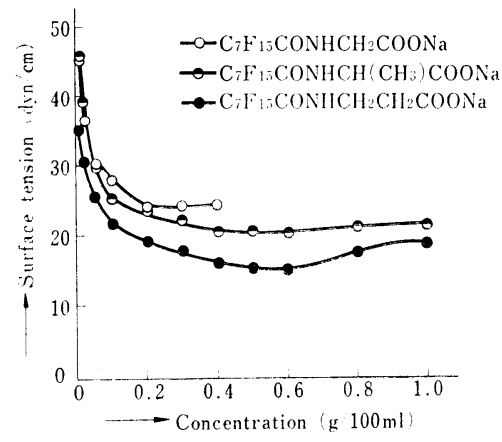

Fig.-1 Surface tension curves of sodium salts of $N$-per $=$ fluorooctanoylamino acids at $30^{\circ} \mathrm{C}$.

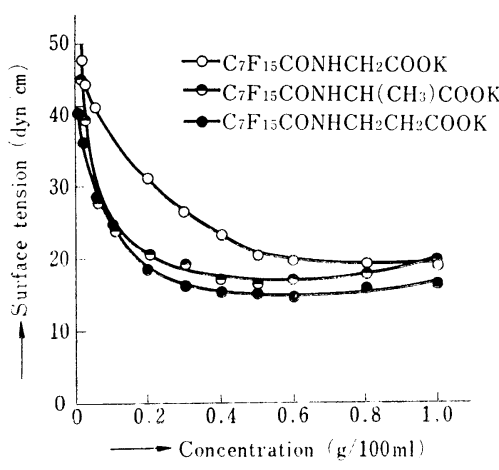

Fig. - 2 Surface tension curves of potassium salts of $N$-per= fluorooctanoylamino acid.
Table 3 Critical micelle concentration (cmc) and Krafft point of $N$-perfluoro= octanoylamino acid salt $\left(\mathrm{C}_{7} \mathrm{~F}_{15} \mathrm{CO}=\right.$ NHRCOOM)

\begin{tabular}{c|c|c|c}
\hline \multicolumn{2}{c|}{ Surfactant } & cinc $10^{3}$ & $\begin{array}{c}\text { Krafft point } \\
\left({ }^{\circ} \mathrm{C}\right) \\
(19 \%)\end{array}$ \\
\hline $\mathrm{R}$ & $\mathrm{M}$ & $(\mathrm{M})$ & 60 \\
$\mathrm{C} \mathrm{CH}_{2}$ & $\mathrm{Na}$ & - & 26 \\
& $\mathrm{~K}$ & 10.9 & 93 \\
& $\mathrm{Li}$ & - & $<0$ \\
$\mathrm{CH}\left(\mathrm{CH}_{3}\right)$ & $\mathrm{Na}$ & 10.51 & $<0$ \\
& $\mathrm{~K}$ & 8.73 & 68 \\
\hline & $\mathrm{Li}$ & 9.67 & 40 \\
& $\mathrm{Na}$ & 10.88 & $<0$ \\
$\mathrm{CH}_{2} \mathrm{CH}_{2}$ & $\mathrm{~K}$ & 10.18 & 76 \\
& $\mathrm{Li}$ & - & \\
\hline
\end{tabular}

alanine derivatives, especially the latter, showed much better properties in surface tension reduc= tion suggesting the significant chain effect in the hydrophobic group.

\section{$3 \cdot 3 \mathrm{cmc}$}

The values of $\mathrm{cmc}$ determined at $30^{\circ} \mathrm{C}$ are presented in Table 3. The cme decreased in the order of $\mathrm{Na}>\mathrm{Li}>\mathrm{K}$ for the $\alpha$ alanine derivatives.

\section{$3 \cdot 4$ Krafft point}

Krafft point (Table-3) was also affected by the kind of metal. Thus, the lithium salt showed the highest Krafft point as anticipated from the poor solubility in water. The lowest $\mathrm{Krafft}$ point of $\alpha$-alanine is considered to be caused by the branched hydrophobic group.

Table-4 Wettability of $N$-perfluorooctanoylamino acid salts $\left(\mathrm{C}_{7} \mathrm{~F}_{15} \mathrm{CONHRCOOM}\right)$ at $30^{\circ} \mathrm{C}$ (Sinking time, s)

\begin{tabular}{|c|c|c|c|c|c|c|c|c|c|}
\hline \multicolumn{2}{|c|}{ Surfactant } & \multicolumn{8}{|c|}{ Concentration $(\mathrm{g} / 100 \mathrm{ml})$} \\
\hline $\mathrm{R}$ & M & 0.1 & 0.2 & 0.3 & 0.4 & 0.5 & 0.6 & 0.8 & 1.0 \\
\hline \multirow{3}{*}{$\mathrm{CH}_{2}$} & $\mathrm{Na}$ & -300 & $>300$ & $>300$ & -300 & - & - & 一 & 一 \\
\hline & K & $2.3(0)$ & $-3(3)()$ & $3(0)$ & $=30(0)$ & $3(0)$ & $3(x)$ & $3(x)$ & -300 \\
\hline & $\mathrm{Li}$ & $\therefore 3(0)$ & - & - & $\cdots$ & $-\cdots$ & - & $\cdots$ & - \\
\hline \multirow{3}{*}{$\mathrm{CH}\left(\mathrm{CH}_{3}\right)$} & $\mathrm{Na}$ & $\therefore 3()()$ & 21 & $1: 2$ & 5 & 3 & 2 & $\because$ & 1 \\
\hline & $\mathrm{K}$ & $\therefore(x)$ & 26 & 11 & 1 & $\because$ & $\because$ & $\ddot{2}$ & 1 \\
\hline & $\mathrm{L}, \mathrm{i}$ & $3(x)$ & $23(x)$ & 28 & 9 & 1 & 3 & 2 & 2 \\
\hline \multirow{3}{*}{$\mathrm{CH}_{2} \mathrm{CH}_{2}$} & $\mathrm{Na}$ & $>300$ & $=300$ & 60 & 45 & 15 & 6 & 6 & 5 \\
\hline & $\mathrm{K}$ & $>300$ & $>300$ & $>300$ & $>300$ & 26 & 15 & 13 & 9 \\
\hline & $\mathrm{Li}$ & $>300$ & $>300$ & 73 & 33 & 20 & - & - & - \\
\hline
\end{tabular}




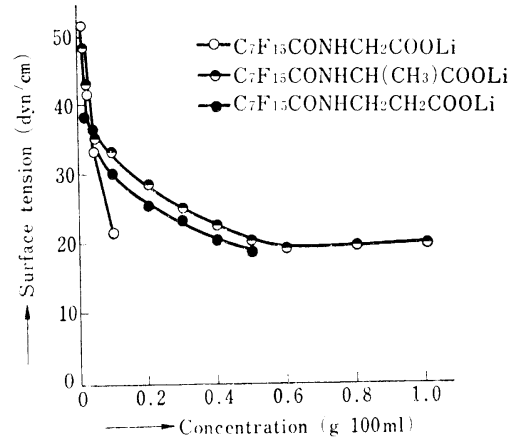

Fig. 3 Surface tension curves of lithium salts of $N$-perfluorooctanoylamino acids at $30^{\circ} \mathrm{C}$.

Table-5 ()il repellency of $\mathrm{N}$-perfluorooctanoyle amino acid salt $\left(\mathrm{C}_{7} \mathrm{~F}_{15} \mathrm{CONHRCOOM}\right)$

\begin{tabular}{|c|c|c|c|}
\hline \multicolumn{2}{|c|}{ Surfactant } & \multicolumn{2}{|c|}{ Oil repellency } \\
\hline $\mathrm{R}$ & M & Adhesion $(\%)$ & Rating \\
\hline \multirow{9}{*}{$\mathrm{CH}_{2}$} & \multirow{3}{*}{$\mathrm{Na}$} & 1.83 & 100 \\
\hline & & 0.34 & 60 \\
\hline & & 0.21 & 50 \\
\hline & \multirow{3}{*}{ k } & 9.49 & 100 \\
\hline & & 2.29 & 100 \\
\hline & & (). 18 & () \\
\hline & \multirow{3}{*}{ Li } & 1.88 & (i) \\
\hline & & 0.90 & 50 \\
\hline & & $0.26 j$ & 0 \\
\hline \multirow{9}{*}{$\mathrm{CH}\left(\mathrm{CH}_{3}\right)$} & \multirow{3}{*}{$\mathrm{Na}$} & 2.21 & 100 \\
\hline & & 1.59 & 100 \\
\hline & & 0.22 & 100 \\
\hline & \multirow{3}{*}{$\mathrm{K}$} & 2.22 & 100 \\
\hline & & 1.59 & 100 \\
\hline & & 0.95 & 100 \\
\hline & \multirow{3}{*}{$\mathrm{Li}$} & 3.16 & 100 \\
\hline & & 1.57 & 100 \\
\hline & & 1.30 & 90 \\
\hline \multirow{9}{*}{$\mathrm{CH}_{2} \mathrm{CH}_{2}$} & \multirow{3}{*}{$\mathrm{Na}$} & 3.34 & 100 \\
\hline & & 1.65 & 100 \\
\hline & & 0.75 & 100 \\
\hline & \multirow{3}{*}{ K } & 2.81 & 100 \\
\hline & & 1.96 & $10(1)$ \\
\hline & & $0.5 \%$ & 10() \\
\hline & \multirow{3}{*}{$\mathrm{Li}$} & 2.41 & 100 \\
\hline & & 1.25 & 100 \\
\hline & & 0.40 & 70 \\
\hline
\end{tabular}

\section{$3 \cdot 5$ Wettability}

A similar feature was observed with regard to the wettability as shown in Table-4. The glycine derivatives showed poor wettability, while $\alpha$-alanine derivative exhibited excellent wettability.

\subsection{Oil repellency}

Oil repellency is another characteristic pro= perty of fluorine-containing surfactant and good property was demonstrated by all surfactant, although, among them, the alanine derivatives were slightly superior to the glycine derivatives as shown in Table-5.

In conclusion, the present results suggest that the $\beta$-alanine derivative is the most excellent surfactant among the three kinds of amino acid derivative.

(Received April 28, 198:)

\section{References}

1) A.M. Schwarz, J.M. Perry, and J. Berch, "Surface Active Agents and Detergents" Vol. II., Robert E. Krieger Publishing Company, Huntington, New York (1977)

2) B.R. Bluestein, R.D. Cowell, and M.L. Mau= sner, J. Am. Oil Chem. Soc., 58, 173 A (1981).

3) M. Takehara, R. Yoshida, and M. Yoshikawa, Cosmetics and Toiletries, 94, 31 (1979).

4) E. Schierer, T'enside, 13, 1 (1976).

5) C. Kimura, K. Murai, K. Kashiwaya, T. Ka= nno, and T. Nishiyama, Yukagaku, 31, 464 (1982).

6) C. Kimura, K. Kashiwaya, K. Murai, N. Sato, and T. Nishiyama, Yukagaku, 32, 258 (1983).

7) C. Kimura, K. Kashiwaya, M. Kobayashi, and T. Nishiyama, J. Am. Oil Chem. Soc., 61, 105 (1984).

8) R.P. Patel and S. Price, J. Org. Chem., 30, 3575 (1965).

9) E.J. Grajeck and W.H. Petersen, Textile Re= search J., 32, 320 (1962). 